\title{
Impact of Land Cover/Use Dynamics on Watershed Flow in Snoqualmie Watershed, King County, WA
}

\author{
Sardorbek Musayev ${ }^{1, *}$, Ilhomjon Musaev $^{2}$, and Mashkhurakhon Nuretdinova ${ }^{3}$ \\ ${ }^{1}$ University of Connecticut, Department of Civil and Environmental Engineering, Storrs, CT, USA \\ ${ }^{2}$ Tashkent Institute of Irrigation and Agricultural Mechanization Engineers, Department of Geodesy \\ and Geoinformatics, Kari Niyazi str., 39, 100000, Tashkent, Uzbekistan \\ ${ }^{3}$ State Research Project Institute "Uzdavyerloyiha", Choponota str., Chilanzar-C massif, Tashkent, \\ 100097 Uzbekistan
}

\begin{abstract}
Water is one of the most important natural resources flow though watersheds. It is expected that within next decade at least 36 states in the US experience water shortages. Preserving and proper management of water and watershed resources is crucial. The objective of this study is to develop SWAT model along with compatible hydrologic programs and calibrate the model to predict the volume and discharge of flow in watershed outlets. Model uses 5 distinct years of land use/cover and weather data to analyse the change in hydrologic processes within thze watershed of Snoqualmie watershed of King county in Washington state. Model shows significant improved predictions for the selected period of time but some certain assumptions suggest the model needs further improvements. Results indicate that land use change and use dynamics have an impact to the watershed flow in Snoqualmie watershed. Results of this study can be used by implementing agencies to manage water and watershed resources in the King county, WA area.
\end{abstract}

\section{Introduction}

Water is one of the most important natural resources flowing through forests. The Forest Service manages the largest single source of water in U.S., with about one-fifth originating from 193 million acres of land [1]. A network of water and watershed resource specialists support stewardship efforts at all levels of the organization to promote healthy, sustainable watersheds fundamental to ecosystems and people. Forests in the United States provide drinking water to more than 180 million people as well as sixty-six million people rely on a national forest as their water source. It is expected that within next 10 years at least 36 US states anticipate water shortages [2]. Hence, it's important to study and preserve the watershed for the next generations. Besides, flood and deforestation are other severe threats to the watershed from mismanagement of forest resources. Some studies show improper land use has an impact to stream flows but other studies propose that silviculture activities

\footnotetext{
*Corresponding author: sardorbek.musayev@uconn.edu
} 
have no bearing to the flood [3]. It is known that deforestation of watershed is becoming a vital concern for floods, river water quality and soil erosion.

Objective of this paper is modeling and visualization of the impact of land cover change over watershed flow. We use SWAT model and calibrate the model with the USGS discharge measurement stations available at the discharge points from the watershed or within the watershed. We used 5 years $(1992,1996,2001,2006$ and 2011) land cover data to analyze the land cover change over this time. 2001 data was selected for the focus point. Weather station data were acquired from 01.01.2002 to 31.12.2005.

\subsection{Study area}

Washington State has faced number of flood events (Fig. 1a) and timber production has also been increasing in the state. The timber production map indicates the county wise production (Fig. 1b).

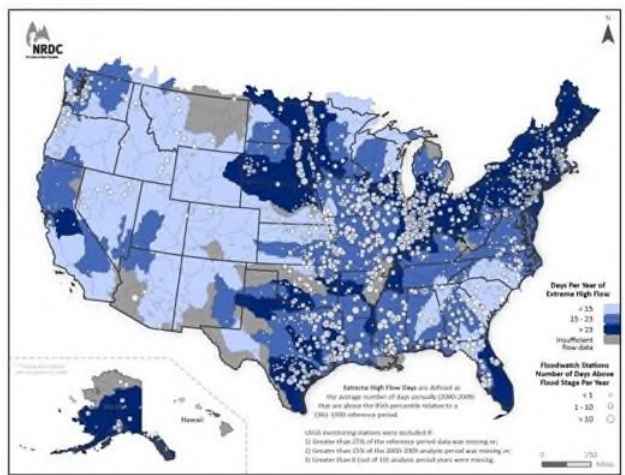

A

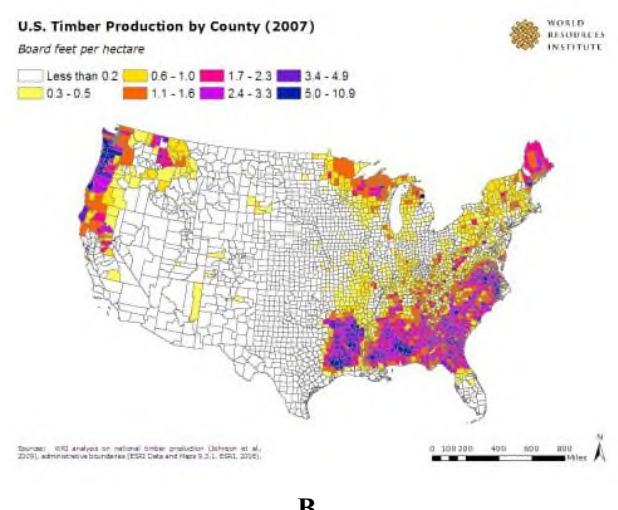

B

Fig. 1. A. Flood Vulnerability Map in US by Watersheds, 2000-2009; B. US County wise Timber Production Map 2007.

King county is selected for this study because it is one of the counties with higher timber production. County receives an average annual precipitation of 80-140 inches (Fig. 2a) which is higher compared to other states. Oregon and Washington states of continental US receives highest average annual precipitation, 122 inches and 115 inches respectively [4]. It is important to note that 22 officially declared floods occurred (Fig. 2b) in Washington state during 1980 to 2010 [5].

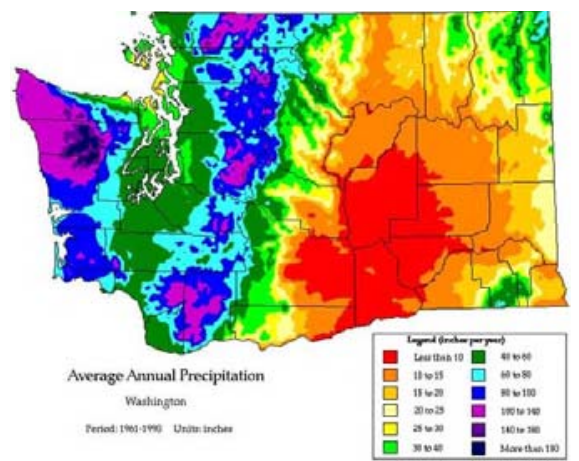

A

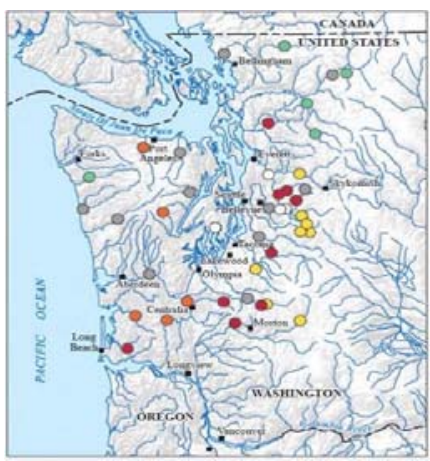

B

Fig. 2. A. Average Annual Precipitation Map for 1961-1990; B. Locations and number of largest floods between 1980 and 2010 in Washington state. 
It can be seen that King County in Washington State is one of the highest risk and vulnerable county to floods (Fig. $3 a$ and $b$ ).

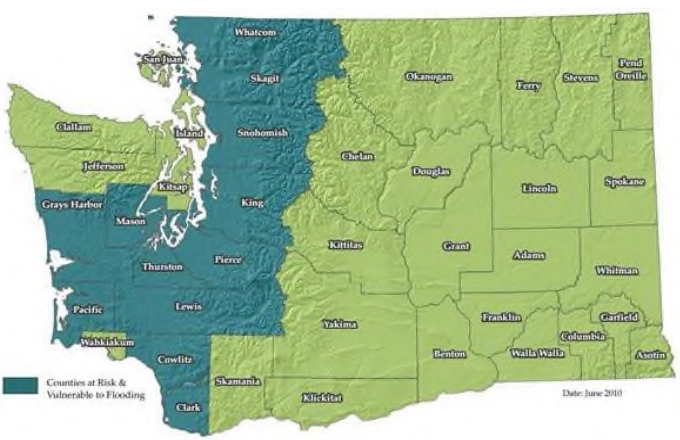

A

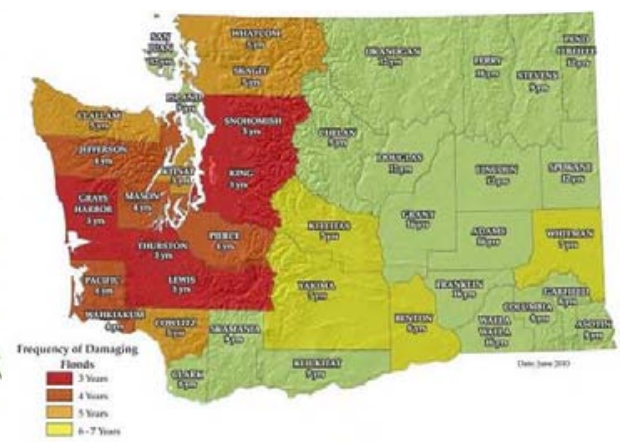

B

Fig. 3. A. Counties at Risk and Vulnerable to Floods in WA; B. Frequency of Flooding Causing Major Damage in WA, 1956 - 2013.

As per watershed, Snoqualmie Watershed is selected because it has all three drivers for better analysis such as high average annual precipitations, timber production and floods. The Snoqualmie watershed is sub basin of bigger Snohomish River watershed which lies within King and Snohomish Counties (Fig. 4).
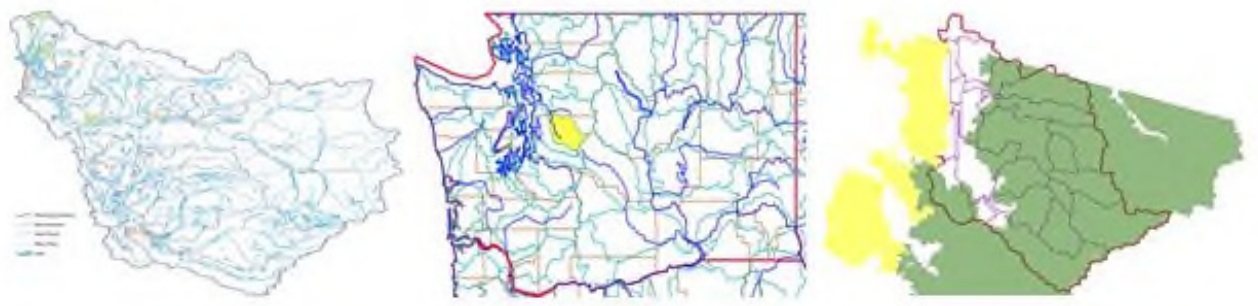

Fig. 4. The Snohomish (Skykomish / Snoqualmie) river watershed. Second image shows the location of Snoqualmie river watershed (yellow) and the third image shows clearing restricted and timber production area (green) within the Snoqualmie watershed.

\subsection{SWAT modeling program}

The Soil and Water Assessment Tool (SWAT) is a small-scale, watershed-to-river-basin model that simulates the quality and quantity of surface and ground water and predicts the environmental impact of land use, land-management practices and climate change. SWAT is a semi-distributed and long term strategic planning tool based on soil types, land use and management practices [6]. SWAT is well compatible with ArcGIS which enables to integrate several geospatial data for precise analysis. Thus, SWAT is basically used for simulation of the processes of hydrology, weather, sedimentation, soil temperature, crop growth, nutrients, pesticides, and agricultural practices. Researchers also use this model for evapotranspiration, surface runoff, infiltration, percolation, shallow aquifer and deep aquifer flow, and channel routing [7]. Thus it is served as an interdisciplinary watershed modeling tool for many research projects [8]. However, some group of researchers found varying sensitivity in model parameters and suggest dynamic update of parameters during the simulation. The same group further indicated that sensitivity of parameters during various flow regimes (low, medium and high flow) is also found to be uneven, which suggests the significance of a multi-criteria approach for the calibration of the model [9]. 


\section{Materials and methods}

Study is conducted in three steps. First, database is developed for 1992, 1996, 2001, 2006 and 2011 years and then land cover maps were generated to learn land cover dynamics. Second, a SWAT simulation run was carried out using a set of established data base and other input variables. Third, along with the calibration the efficiency of the model was assessed by comparing simulated and observed daily flow and using the Nash Sutcliffe and determination coefficient $\left(\mathrm{R}^{2}\right)$ methods. The following tools were used to carry out for modeling purposes: Arc SWAT - used as core program of the entire modeling process, BASIN 4 - used for obtaining the watershed basic data, Google EARTH - as a reference program to refer the locations, WMS 8.1 - used for delineation and compare watershed with SWAT delineation.

\subsection{Data}

The modeling started from obtaining the necessary data from the required sources. The following data sets were obtained from the different sources (Fig. 5):

- NED DEM data from United States Geological Survey (USGS);

- Weather data from National Climatic Data Center of National Oceanic and Atmospheric Administration (NOAA) for the period of 01.01.2002 to 31.12.2005

- Land cover and Land Use data from NLCD for 1992, 1996, 2001, 2006 and 2011;

- Soil data from the National Resource Conservation Service of United States Department of Agriculture (USDA);

- Stream flow discharge data from National Water Information System of USGS
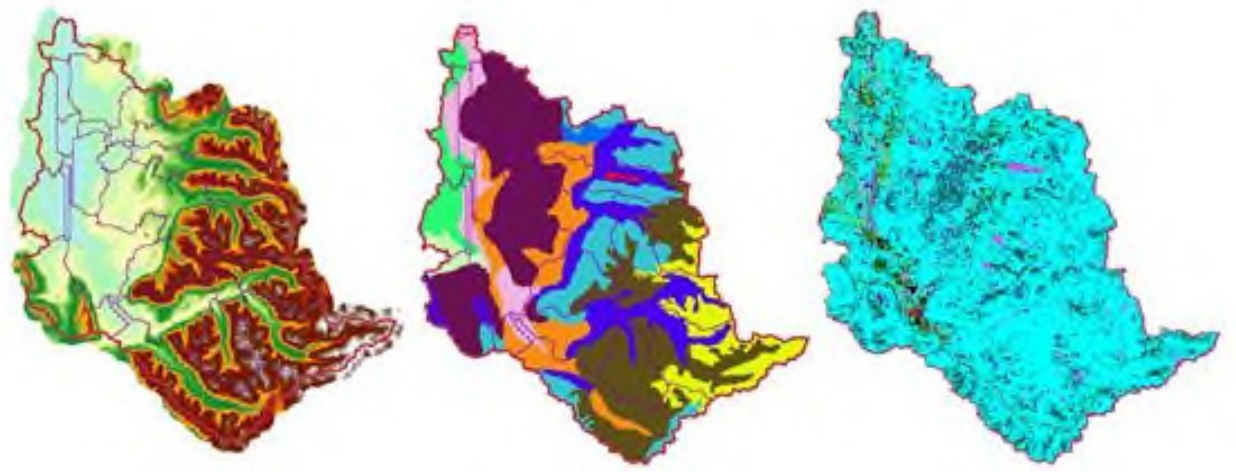

Fig. 5. DEM, Soil and Land Cover Data after Watershed delineation.

During the weather data collection process it was found that only 4 weather stations out of 21 had full weather station data for the required period (Fig. 6). As per stream flow data only 2 stations were selected despite of quite good number of other stations located within the watershed due to matching with the outlets produced by SWAT after delineation. The look up tables for land cover data all years were manually generated as they were not available with land cover data, however there was information about the percentage share of various land cover features. For January and February months we used 0.1/1.1 inches whereas for March and April months we used 0.1/0.6 inches conversion ratio based on the literature review $[10,11]$. 

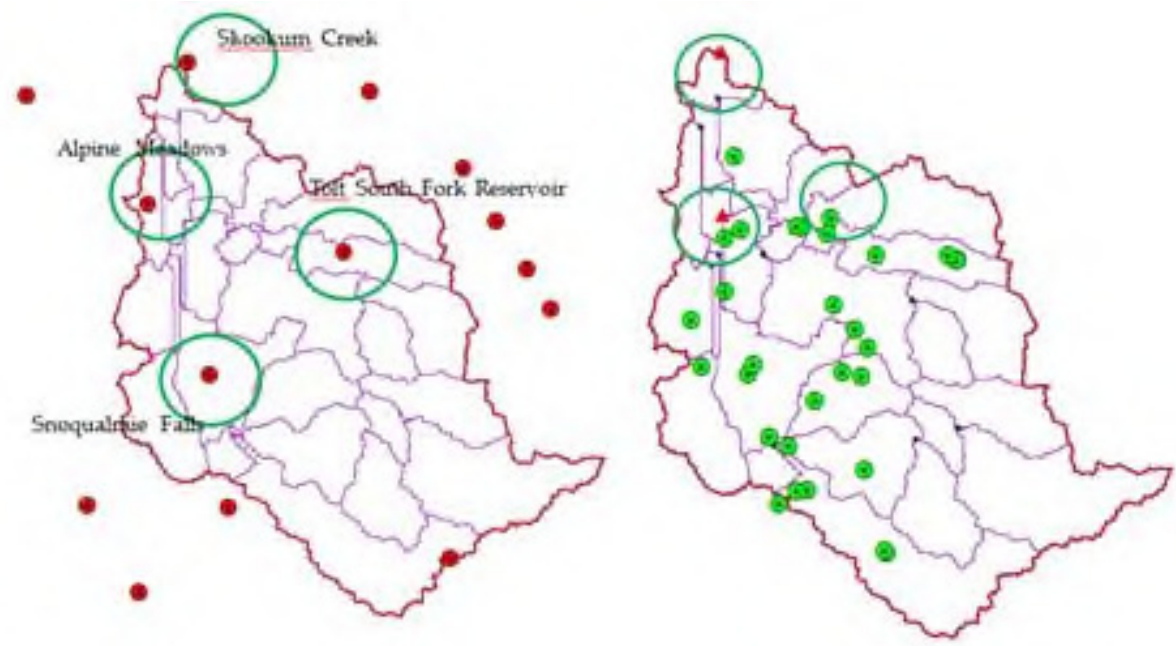

Fig. 6. Location of weather stations and stream flow gauges within watershed.

\subsection{Model Setup}

The watershed and sub watershed delineations were performed using $30 \mathrm{~m}$ resolution DEM data using ArcSWAT model watershed delineation function. The watershed delineation process consists of five major steps, DEM setup, stream definition, outlet and inlet definition, watershed outlets selection and definition and calculation of sub basin parameters. After the DEM setup was completed and the location of outlet was specified on the DEM, the model automatically calculates the flow direction and flow accumulation. Subsequently, stream networks, sub watersheds and topographic parameters were calculated using the respective tools. The stream definition and the size of sub basins were carefully determined by selecting threshold value suggested by the ArcSWAT interface (3,536.2 hectares), the Snoqualmie watershed was delineated in to 27 sub watersheds having an estimated total area of $176,810.8$ ha (Figure 6). However, the total area of the watershed as per the information received from King County Snoqualmie Watershed Coordinator was 175,229.2 ha. There is a slight deviation between the delineated map and the retrieved map from watershed authority. The difference in the total area between the delineated and the database may be due to the difference in the DEM resolution or the watershed delineator model used. Furthermore the model setup was a bit complicated due to the South Fork Tolt Reservoir within the Snoqualmie watershed.

The sub watersheds were divided into hydrologic response units (HRU) by assigning the threshold values of land use and land cover, soil and slope percentage. Land cover, soil and slope characterization for the watershed was carried out using commands from the HRU analysis menu on the Arc SWAT Toolbar. These tools allowed loading land cover (.img format) and soil data (shape file) into the project interface, evaluates slope characteristics and determining the land cover/soil/slope class combinations in the delineated sub watersheds. In the model, there are two options in defining HRU distribution: assign a single HRU to each sub watershed or assign multiple HRUs to each sub watershed based on a certain threshold values. The SWAT user's manual suggests that $5 \%$ land use threshold, $20 \%$ soil threshold and $20 \%$ slope threshold are adequate for most modeling application. Thus, the focus watershed was divided into 261 HRUs with unique land use and soil combinations. 
Furthermore the model requires the daily values of all climatic variables from measured or generated data. In order to fulfill this requirement the weather data was acquired from NOAA web site for following the 4 stations: Skookum Creek, Alpine Meadows, Tolt South Fork Reservoir and Snoqualmie Falls. Then, weather data for these stations with continuous records from 01.01.2002 to 31.12.2005 were used as an input data. Precipitation, maximum/minimum temperature values, relative humidity data, solar radiation data and wind speed data were used from the ArcSWAT database.

\section{Results and discussion}

atershed simulated and observed flow for the selected period of time (01.01.2002 01.01.2005) (Fig. 7) and output results for a sample period from 01.01.02 to 31.12.02 (Fig. 8) produced close relationships. For evaluation of model simulation outputs the preliminary assessment was carried out for "major outlet" out of two outlets using the NSC and $\mathrm{R}^{2}$ methods. Assessment results for the NSC and $\mathrm{R}^{2}$ values were obtained as 0.0168 and 0.622 respectively. NSC shows about 0.02 which is not a very good indicator for the goodness of the model despite of $\mathrm{R}^{2}$ being 0.62 .

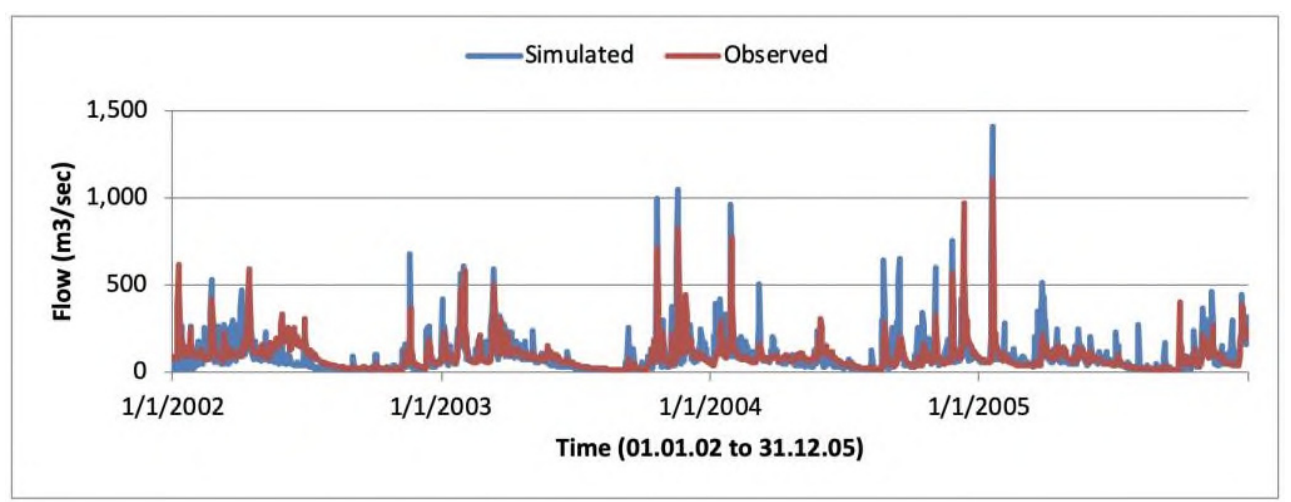

Fig. 7. Run \#1 output graphical representation and comparison with observed data.

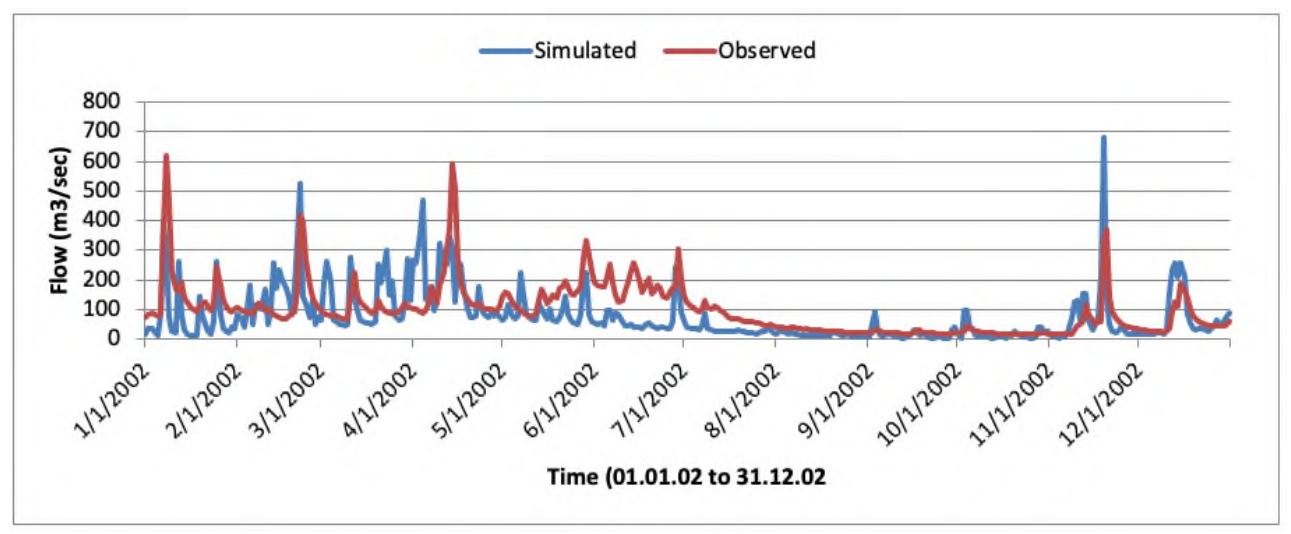

Fig. 8. The Run \#1 output for the period from 01.01.02 to 31.12.02. 


\subsection{Model Evaluation}

For evaluation of the model with respect to the simulated vs observed data the assessment, goodness of fit, is conducted. For this step the Nash-Sutcliffe coefficient and determination coefficient $\left(\mathrm{R}^{2}\right)$ methods were used and they are calculated based on the following formulas $(1,2)$ :

$$
R^{2}=\frac{\sum\left[X_{i}-X_{a v}\right]\left[Y_{i}-Y_{a v}\right]}{\sqrt{\Sigma\left[X_{i}-X_{a v}\right]^{2}} \sqrt{\Sigma\left[Y_{i}-Y_{a v}\right]^{2}}},
$$

where, $X_{i}$ - measured; $X_{a v}$ - average measured; $Y_{i}$ - simulated and $Y_{a v}$ - average simulated values.

$$
N S C=1-\frac{\Sigma\left(X_{i}-Y_{i}\right)^{2}}{\Sigma\left(X_{i}-X_{a v}\right)^{2}},
$$

where, $X_{i}$ - measured value; $Y_{i}$ - simulated value and $X_{a v}$ - average observed values.

$\mathrm{R}^{2}$ ranges from 0 to 1 being poor to good respectively, with higher values indicating less error variance, and typical values greater than 0.6 are considered acceptable. In case of NSC values which range from 1 to negative $\infty$ values. And similar to above NSC equal to 0 or less, then the model prediction is no better than using average annual runoff volume as a predictor of runoff. Results between zero and one are indicative of the most efficient parameters for model predictive ability, and NSC values of 1 indicate perfect alignment between simulated and observed values.

\subsection{Model Calibration}

Model calibration is required to optimize the values of the model parameters which helps to reduce the uncertainty in the model outputs. However, such model with multiple parameters, the challenging task is to determine which parameters need to be calibrated. Here, the sensitivity analysis would be the best option to deal with and find out which parameters need to be calibrated in order to improve the model. We used different ArcSWAT parameters for calibration ranges (Table 1).

Table 1. Calibration parameters.

\begin{tabular}{|c|c|c|}
\hline Parameter & Interval & Selected \\
\hline Alpha_bf & 0.001 to 0.16 & 0.16 \\
\hline Cn2 & 0 to $-15 \%$ & $-15 \%$ \\
\hline Ch N2 & 0.014 to 0.16 & 0.16 \\
\hline Canmx & 0 to 100 & 10 \\
\hline Esco & 0.1 to 1.0 & 0.75 \\
\hline SMTMP & -5 to +5 & 5 \\
\hline SFTMP & -5 to +5 & 0 \\
\hline Surlag & 0.1 to 12 & 0.2 \\
\hline Sol_Awc & 0.20 to 0.50 & 0.2 \\
\hline Slope & -50 to $-25 \%$ & $-30 \%$ \\
\hline
\end{tabular}

Under this procedure, parameter values were adjusted by changing one or two parameters at a time within the allowable ranges either by replacement the initial value or addition or by multiplication of the initial value from the interface input. 


\subsection{Model Outputs and Calibration}

\subsubsection{Formatting the title}

The following charts represent different flow results in the watershed land cover under different years in Fig. 9.
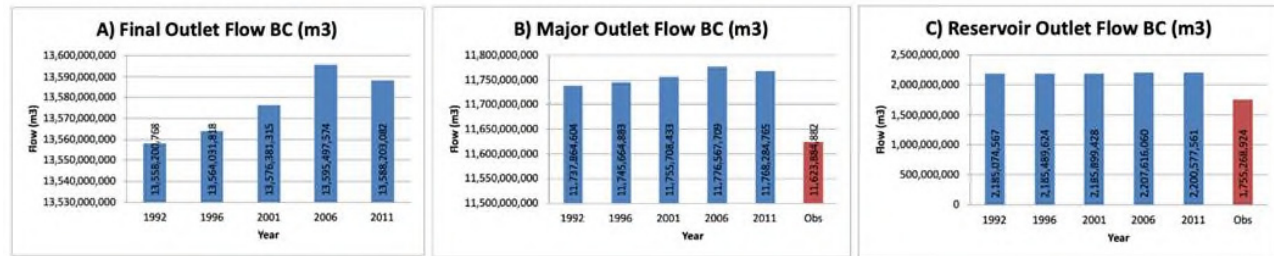

Fig. 9. Comparison of the flow at the final outlet from watershed before calibration.

Model outputs on watershed final flow indicates that watershed flow increased in all three outlets except year 2011. Fig. 9 b and c include observed flow information for comparison purpose retrieved from USGS stations. Model outputs in Fig. 10 a, b, and c also shows the progress of flow volume in all years.
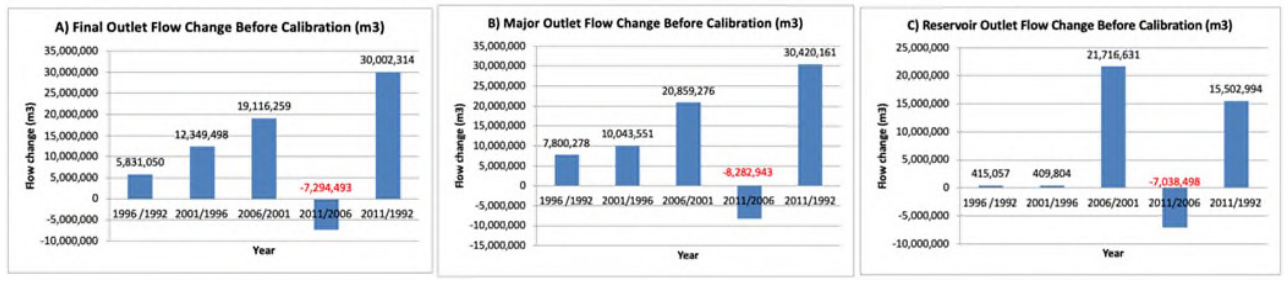

Fig. 10. Charts of flow change with respect to previous year before calibration.

The charts show that the increase of flow as land cover also kept increasing in all three outlets of the watershed except 2011 with respect to 2006 where flow shows negative tendency. There is significant increase in flow under the same weather data set for 2011 to 1992 relationship. Total flow discharges $(\mathrm{m} 3 / \mathrm{sec})$ was also analyzed and compared (Fig. 11 $\mathrm{a}, \mathrm{b}$, and c).
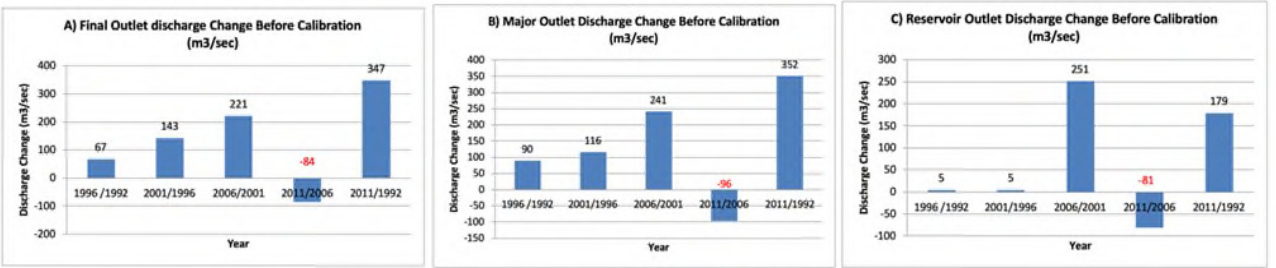

Fig. 11. Charts of flow discharge change with respect to previous year before calibration.

\subsubsection{After Calibration (AC)}

Upon calibration steps with required parameters the following flow changes observed in the watershed (Fig. 12 a, b, and c). We also observed increase in flow in all outlets. 

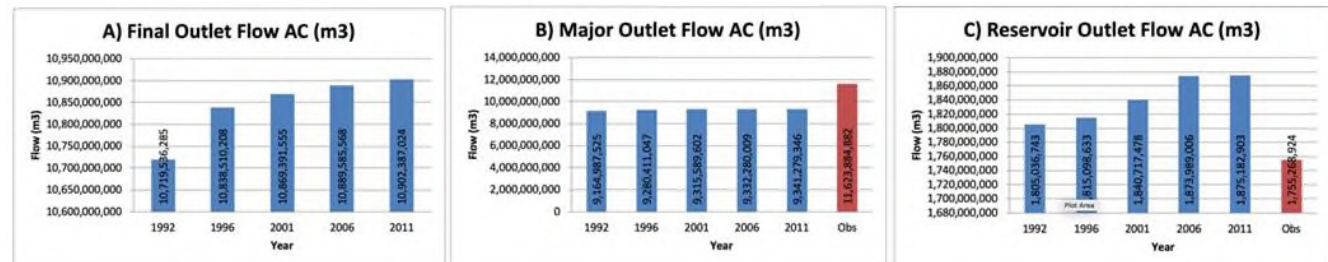

Fig. 12. Charts of flow discharge change with respect to previous year before calibration.

Before calibration model outputs were giving higher tendency of flow increases at final and major outlets whereas after calibration outlet flows increase are not rising with the same ratio. However, reservoir outlet is showing the opposite scenario. Nevertheless, model flow outputs keep increasing after model calibration as land cover changes from 1992 to 2011 period. Same pattern of flow increases were observed in flow discharge increase ration (Fig. 13 a, b, and c).
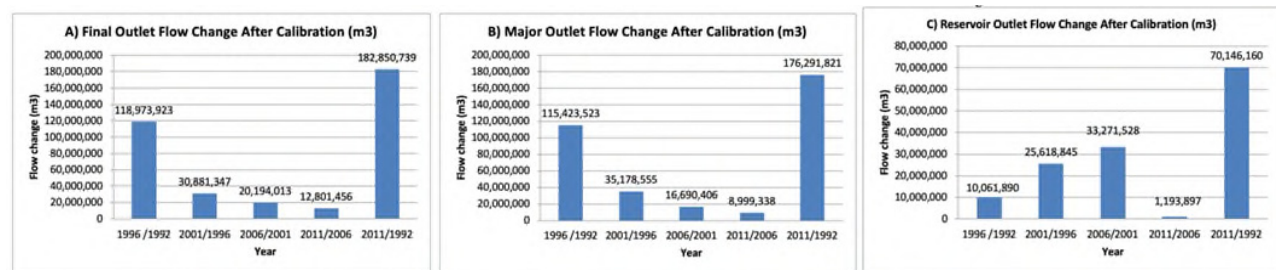

Fig. 13. Charts of flow change with respect to previous years after calibration.

This explains that under improved model setup all five years flow patterns showed increase order especially in major and reservoir outlets (Fig. $14 \mathrm{a}, \mathrm{b}$, and c).
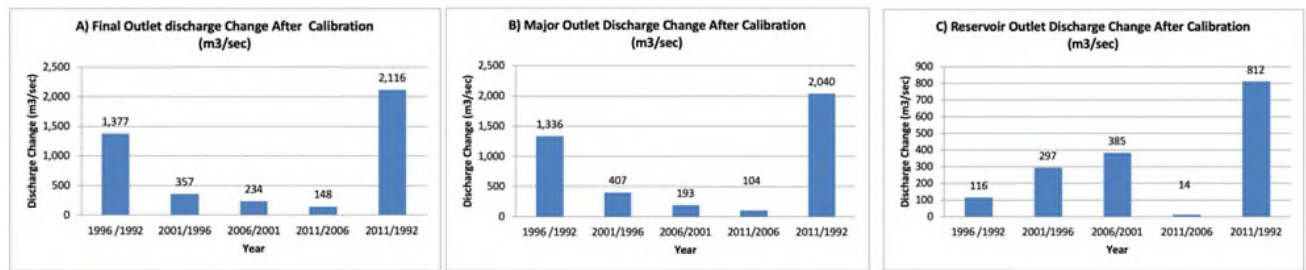

Fig. 14. Charts of discharge change with respect to previous years after calibration.

The essential part of the model calibration is to see how improved model can predict the upcoming scenarios. Here, one can see the percent change of simulated flow with respect to observed flow at two calibration outlets. This comparison would give us better picture or visualization how much (more or less) percentage the calibrated flow has changed than the observed flow before and after the model calibration (Fig. $15 \mathrm{a}$ and b). 


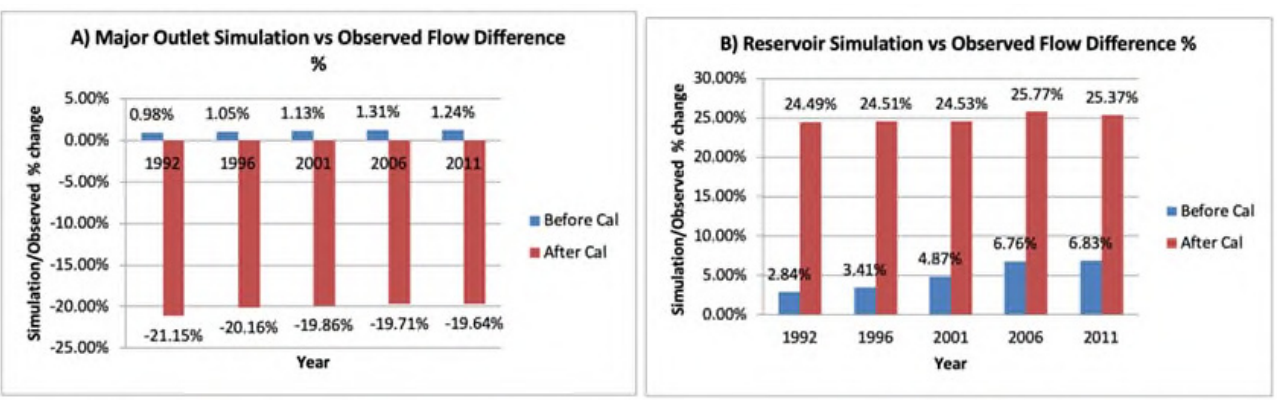

Fig. 15. Charts of percentage change of simulated vs observed flow before and after model calibration.

Charts in Fig. 15a shows higher simulated flows than the observed flows in both outlets before the model calibration whereas they show less after calibration in major outlet. However, the reservoir outlet keeps increasing flow in simulated scenarios than actual observed values.

Despite of the NSC and $\mathrm{R}^{2}$ values showing significantly higher values after calibration compared to previous analysis (Table 2) it is suggested that the model shows positive correlation in some but it may still suggest improvements for better improved predictions (Fig. 16 and 17).

Table 2. Calibration parameters.

\begin{tabular}{|c|c|c|c|c|c|c|c|c|}
\hline \multicolumn{5}{|c|}{ Before Calibration } & \multicolumn{4}{|c|}{ After Calibration } \\
\hline \multirow{2}{*}{$\begin{array}{c}\text { Land } \\
\text { Cover } \\
\text { Data } \\
\text { Year }\end{array}$} & \multicolumn{2}{|c|}{ NSC } & \multicolumn{2}{|c|}{$\mathbf{R 2}$} & \multicolumn{2}{|c|}{ NSC } & \multicolumn{2}{|c|}{$\mathbf{R 2}$} \\
\hline & $\begin{array}{r}\text { Major } \\
\text { outlet }\end{array}$ & $\begin{array}{c}\text { Reservoir } \\
\text { outlet }\end{array}$ & $\begin{array}{c}\text { Major } \\
\text { outlet }\end{array}$ & $\begin{array}{c}\text { Reservoir } \\
\text { outlet }\end{array}$ & $\begin{array}{l}\text { Major } \\
\text { outlet }\end{array}$ & $\begin{array}{c}\text { Reservoir } \\
\text { outlet }\end{array}$ & $\begin{array}{c}\text { Major } \\
\text { outlet }\end{array}$ & $\begin{array}{c}\text { Reservoir } \\
\text { outlet }\end{array}$ \\
\hline 1992 & -0.01 & -1.28 & 0.62 & 0.73 & 0.49 & 0.43 & 0.73 & 0.76 \\
\hline 1996 & 0.00 & -1.21 & 0.62 & 0.73 & 0.53 & 0.37 & 0.76 & 0.78 \\
\hline 2001 & 0.02 & -1.08 & 0.62 & 0.73 & 0.53 & 0.41 & 0.75 & 0.78 \\
\hline 2006 & -0.01 & -1.30 & 0.62 & 0.73 & 0.52 & 0.27 & 0.75 & 0.77 \\
\hline 2011 & -0.01 & -1.24 & 0.62 & 0.73 & 0.53 & 0.43 & 0.76 & 0.78 \\
\hline
\end{tabular}
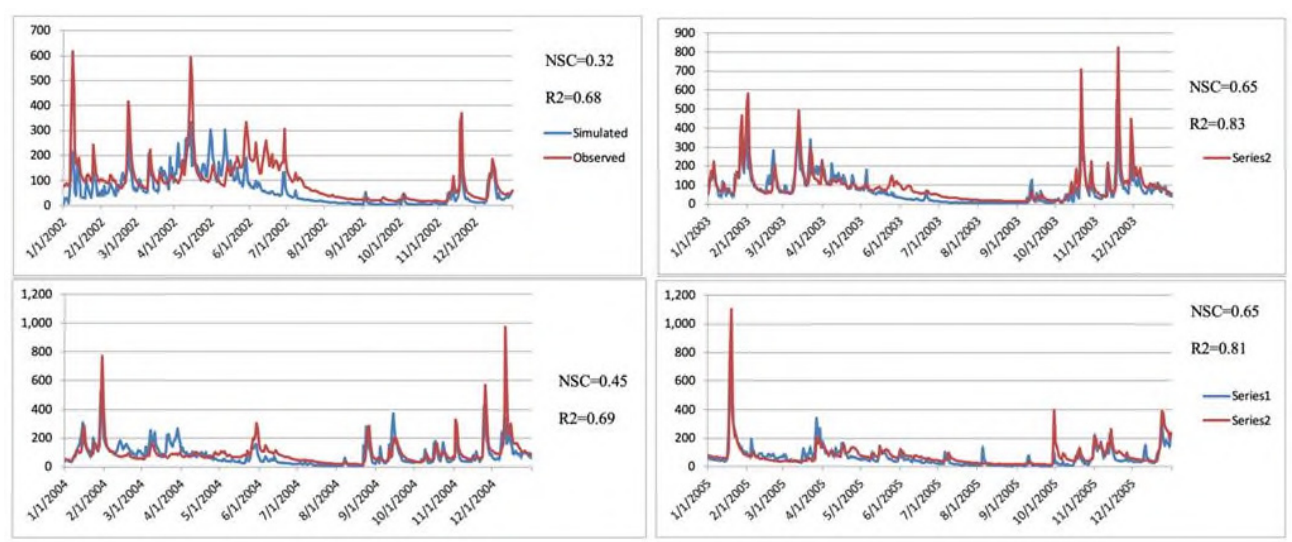

Fig. 16. Yearly breakdown of simulated/observed graph on 2001 land cover from major outlet. 

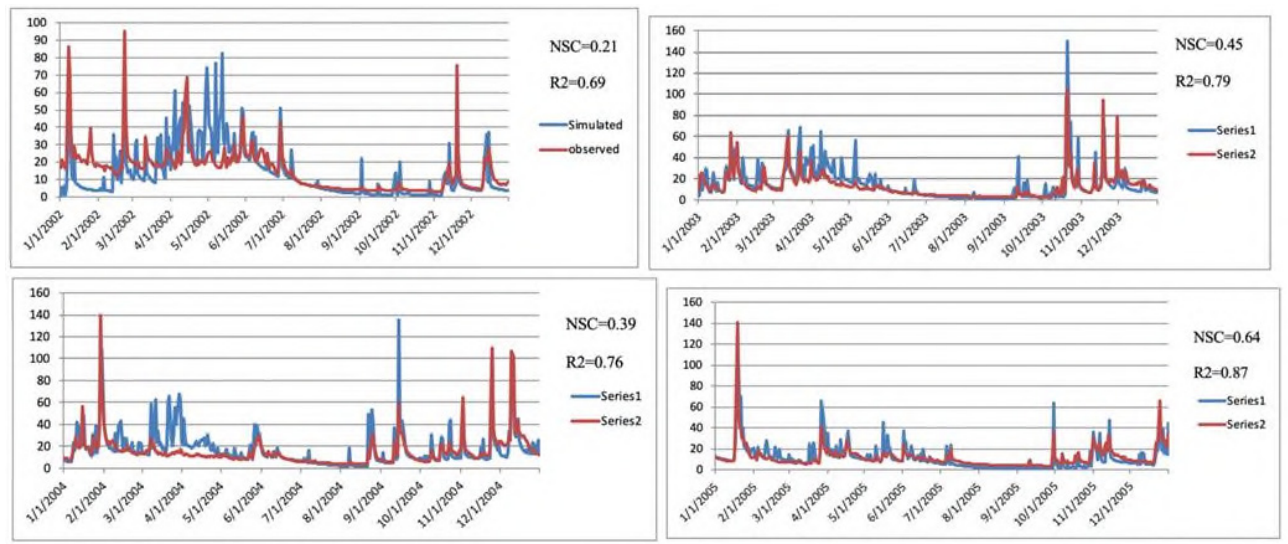

Fig. 17. Yearly breakdown of simulated/observed graph on 2001 land cover from reservoir outlet.

\section{Conclusions}

SWAT modeling program was used to simulate the watershed outlet flows to predict the flow along with other compatible programs. Model calibration enabled to run sensitivity analysis. Model shows significant improved predictions for the selected period of time but some certain assumptions suggest the model needs further improvements. The main conclusion of the study is that land use change and use dynamics have an impact to the watershed flow in Snoqualmie watershed in King county of Washington state. It is also noticed from the HRU Land/Soil Reports that reduction of forested area indicating higher watershed flows in outlets. However, it is still arguable whether major weather related floods occur due to higher precipitation in the region or some other factors influence in hydrologic processes of the watershed. Any further research on this topic should include more climate and flow data along embracing more years for better predictions. Results of this study can be used by implementing agencies to manage water and watershed resources in the King county, WA area.

\section{References}

1. C. Opp, M. Groll, I. Aslanov, T. Lotz, N. Vereshagina, Quaternary International, 429, 86-99 (2017)

2. B. Alikhanov, S. Alikhanova, R. Oymatov, Z. Fayzullaev, A. Pulatov, IOP Conf. Ser.: Mater. Sci. Eng., 883(1), 012088 (2020)

3. G. B. Dodds, Journal of American History, 56(1), 59-69, 1969

4. B. Sh. Matyakubov, Z. J. Mamatkulov, R. K. Oymatov, U. N. Komilov, G. E. Eshchanova, InterCarto, InterGIS, 26, 229-239 (2020)

5. I. Musaev, A. Bokiev, M. Botirova, E3S Web Conf., 227, 05004 (2021)

6. Z. Mamatkulov, E. Safarov, R. Oymatov, I. Abdurahmanov, M. Rajapbaev, E3S Web Conf., 227, 03001 (2021)

7. J. G. Arnold, R. Srinivisan, R. S. Muttiah, P. M. Allen, J. American Water Resources Assoc., 34(1), 73-89 (1998)

8. J. G. Arnold, P. W. Gassman, M. J. White, In Proc. 21st Watershed Technology Conf.: Improving Water Quality and Environment, 701P0210cd (2010) 
9. R. Cibin, K.P. Sudheer, I. Chaubey, Hydrological Processes, 24(9), 1133-1148 (2009)

10. C. Konrad, D. Booth, American Fisheries Society Symposium, 47,157-177 (2005)

11. C. Konrad, D. Booth, S. Burges, WRR, 41, WO7009 (2005) 